\title{
SOBRE O NARCISISMO COMO CAMPO DE PESQUISA: VARIAÇÕES DA TÉCNICA PSICANALÍTICA E DESDOBRAMENTOS CLÍNICOS ${ }^{1}$
}

\section{PERLA KLAUTAU ${ }^{1}$}

\section{Perla Klautau}

${ }^{1}$ Universidade Veiga de Almeida (UVA), Professora do Programa de Mestrado Profissional e de Doutorado em Psicanálise, Saúde e Sociedade, Rio de Janeiro/RJ, Brasil
RESUMO: A proposta deste artigo é investigar o alargamento do raio de ação do método psicanalítico a partir da exploração do narcisismo como campo de pesquisa. Para tal, será efetuado um recuo aos primórdios da constituição da subjetividade, mais precisamente a uma época do desenvolvimento infantil que antecede o estabelecimento do status de unidade do eu. Esse avanço para trás amplia as possibilidades de escuta do material inconsciente não representado, abrindo o caminho para a inserção da qualidade da presença do analista no processo de associatividade.

Palavras-chave: narcisismo, associação livre, representação, atenção flutuante, neutralidade.

Abstract: On narcissism as a field of research: variations on psychoanalytic technique and clinical extensions. The purpose of this article is to investigate the action scope extension of the psychoanalytic method from the exploration of narcissism as a field of research. To do so, a retreat will be made to the beginnings of the constitution of subjectivity, precisely the fase of child development that precedes the establishment of self-unity status. This backward investigation broadens the listening possibilities of the unconscious material, opening the space for the quality of the analyst's presence in the process of associativity.

Keywords: narcissism, free association, representation, suspended attention, neutrality.

DOI - http://dx.doi.org/10.1590/S1516-14982018003008

Todo o conteúdo deste periódico, exceto onde estiver identificado, está licenciado sob uma Licença Creative Commons (cc by 4.0)

\footnotetext{
${ }^{1}$ Este trabalho é parte da pesquisa homônima, financiada pela FUNADESP, desenvolvida no Laboratório de Estudos em Psicanálise e Conexões Interdisciplinares (Lepci).
} 
O método psicanalítico foi concebido para o tratamento dos casos de histeria. Diante da dificuldade crescente em usar a técnica hipnótica como ferramenta clínica ao longo do processo de cura, Freud passou a adotar uma atitude investigativa como via de acesso à causalidade dos sintomas examinados. Ao longo dos casos expostos, na publicação dedicada aos estudos iniciais sobre histeria, a hipnose foi adotada como ferramenta clínica e gradualmente foi sendo abandonada e substituída por uma espécie de conversação sobre as origens dos sintomas apresentados. A mudança efetuada teve o propósito de obter acesso aos conteúdos inconscientes de maneira direta, isto é, sem o uso da hipnose nem de qualquer outro tipo de ferramenta que se valesse da sugestão. Por conta disso, os pacientes passaram a ser estimulados a falar livremente, sem ter a preocupação de estabelecer uma relação de causalidade entre o material comunicado. Em contrapartida, coube ao médico estar atento ao simbolismo contido no discurso endereçado a ele.

É possível localizar nessa atitude o nascimento dos três principais pilares que estruturam o método psicanalítico: a associação livre, a atenção flutuante e a interpretação. O manejo do método psicanalítico é sustentado pela livre associação de ideias por parte do analisando, pela atenção flutuante e pela interpretação do material inconsciente recalcado por parte do psicanalista. Com o estabelecimento deste instrumental, ficou conferida ao analista a tarefa de descortinar o véu encobridor da realidade psíquica, ou seja, os desejos inconscientes recalcados e as fantasias que exercem determinação sobre a formação dos sintomas. Desta forma, a adoção do método psicanalítico permitiu revelar o drama contido no conflito psíquico expresso a partir da luta entre desejo e defesa, que tem como principal referencial as fantasias edípicas e de castração.

O surgimento de casos que não se alinham a este tipo de descrição colocou em xeque o método concebido para o tratamento das neuroses de defesa. Quando a questão recaiu sobre as problemáticas clínicas cujo sofrimento apresentado em primeiro plano encontrava-se intimamente ligado à esfera narcísica, foi possível observar um tipo de angústia que diferia da angústia neurótica de castração: à medida que o eu não se encontrava integrado como unidade separada do ambiente, a angústia suscitada diante da sensação de perda poderia ser entendida como um temor de aniquilamento, de desmoronamento de um eu que, paradoxalmente, não se encontrava constituído como tal. O aparecimento destes tipos de questões instauraram possibilidades de abertura de novos caminhos na exploração psicanalítica: o narcisismo como campo de pesquisa passou a ter lugar na clínica e, gradativamente, os sofrimentos narcísicos impuseram limites à eficácia do método psicanalítico.

\section{O NARCISISMO COMO CAMPO DE PESQUISA: LIMITES E POSSIBILIDADES CLÍNICAS}

Em virtude da análise da autobiografia do presidente Schreber, Freud dedicou atenção especial à noção de narcisismo e, três anos depois, escreveu um ensaio sobre o tema, estabelecendo o narcisismo como um dos principais conceitos psicanalíticos. O artigo Introdução ao narcisismo (FREUD, 1914/2010), que inicialmente foi escrito como uma resposta a Jung, tomou vulto e ultrapassou os limites de seu propósito inicial. A novidade desse texto consistiu no fato de o investimento libidinal no eu não ser restrito à patologia - neuroses narcísicas - mas, pelo contrário, o investimento da libido no eu passou a ser concebido como parte integrante da constituição subjetiva, isto é, como um princípio de unificação das pulsões parciais autoeróticas que primordialmente coexistiam de modo anárquico, encontrando satisfação no próprio corpo sem recorrer a um objeto externo.

É importante lembrar que, de acordo com o que foi exposto no referido artigo, quando a questão recai sobre o autoerotismo, ainda não é possível fazer referência ao conceito de eu. Este não existe desde os primórdios, precisa ser desenvolvido: “Os instintos autoeróticos, contudo, ali se encontram desde o início sendo, portanto, necessário que algo seja adicionado ao autoerotismo - uma nova ação psíquica - a fim de provocar o narcisismo" (FREUD, 1914/2010, p. 93). A ideia da necessidade de uma nova ação psíquica (contida na passagem transcrita que, por sua vez, se tornou uma das principais referências ao artigo em questão) conferiu ao narcisismo papel fundamental na construção do eu como unidade e, ao mesmo tempo, abriu caminho para investigações a respeito de seu surgimento. Deste 
modo, o narcisismo passou a ocupar um lugar de destaque na teoria e na clínica freudianas: concebido, inicialmente, como um momento do desenvolvimento libidinal do sujeito, o narcisismo se firmou como uma estrutura permanente, remetida ao processo de constituição subjetiva (HERZOG; PACHECOFERREIRA, 2014).

Alguns anos após a publicação do referido artigo, mais precisamente na parte final da conferência XXVII, intitulada Transferência, Freud ([1917]1916-17/1990) avaliou que o método psicanalítico não é eficaz no tratamento de problemáticas narcísicas: "A observação mostra que aqueles que sofrem de neuroses narcísicas não têm capacidade para transferência ou apenas possuem traços insuficientes da mesma" (FREUD, 1917[1916-17]/1990, p. 520). Na lógica adotada por Freud, o estabelecimento de uma relação transferencial produtiva é a condição necessária para que a expectativa do analista seja cumprida, ou melhor, para que as resistências que incidem sobre o material recalcado possam ser eliminadas. Neste ponto, é importante ressaltar que a resistência faz parte do eu e é eliminada quando este reconhece uma interpretação: "Em numerosas doenças nervosas - na histeria, nos estados de ansiedade, na neurose obsessiva - nossa expectativa cumpre-se" (ibidem, p. 510). Em outras palavras, as resistências muitas vezes são vencidas, as barreiras do recalque removidas e, assim, o material inconsciente pode ganhar acesso à consciência. O mesmo não pôde ser observado, tão frequentemente, nos casos em que os sofrimentos narcísicos ocupam lugar de destaque.

O termo sofrimentos narcísicos (ROUSSILLON, 1999; GREEN, 2002/2008; VERTZMAN et al, 2012) vem sendo utilizado para reunir um conjunto amplo e variado de patologias cujo ponto comum remete a percalços no processo de constituição do eu, ocasionando perturbações relacionadas ao reconhecimento de si que, por sua vez, resultam em abalos diretamente ligados à esfera identitária. Ao longo do processo de construção dos contornos do eu, os mecanismos de cisão e de clivagem se constituem como recursos defensivos disponíveis para o enfrentamento de experiências traumáticas. Diferentemente do recalque, a clivagem não opera no domínio da representação e da significação. 0 corolário disto é que, no manejo do atendimento de casos e situações em que os sofrimentos narcísicos apresentam-se em primeiro plano, a rememoração do material clivado não obedece à regra da associação livre. Diferentemente do material recalcado que retorna e, por meio da rememoração, é colocado em palavras, o material clivado é rememorado em ato (ROUSSILLON, 1999). Fato este que descortina limites e impasses em relação ao uso da técnica interpretativa, erigindo obstáculos ao seu funcionamento.

Para analisar problemáticas clínicas nas quais o sujeito se encontra ameaçado em seu sentimento identitário, tornou-se necessário buscar compreender os modos de subjetivação que possuem raízes nas experiências vividas nas fases mais precoces da constituição do psiquismo. Se o tipo de sofrimento observado por Freud durante o tratamento das questões levantadas pelos casos de histeria, fobia e neurose obsessiva não impôs a necessidade de descrever o surgimento do eu, os sofrimentos narcísicos o impeliu a encontrar caminhos que conduzissem às origens da estruturação do eu como unidade. As trilhas abertas por esta investigação, iniciada em 1914, conduziram a modificações na teoria e na clínica a partir da elaboração do conceito de pulsão de morte e da segunda tópica.

Como essas trilhas investigativas foram deixadas abertas, coube a cada um dos psicanalistas pósfreudianos a escolha dos aspectos que deveriam ser privilegiados na teorização de suas preocupações clínicas. Com o intuito de alargar o alcance da técnica analítica para além do terreno das neuroses de defesa e incluir as diferentes manifestações clínicas dos sofrimentos narcísicos, psicanalistas que seguiram diferentes caminhos (WINNICOTT, 1952/2000; BALINT, 1967; BION 1957/1994; LACAN, 197273/1985) foram, cada vez mais, efetuando um recuo aos primórdios da constituição da subjetividade, mais precisamente a uma época do desenvolvimento infantil que antecede o estabelecimento do status de unidade do eu. Tal movimento em direção a um tempo anterior ao estabelecimento da linguagem verbal possibilitou a busca de ferramentas teóricas e clínicas para a compreensão dos sofrimentos narcísicos. 


\section{AVANÇANDO PARA TRÁS: UM RECUO AOS PRIMÓRDIOS DA SUBJETIVIDADE}

Em Introdução ao narcisismo, Freud apresentou a ideia de que o eu organizado sob a forma de uma unidade não existe desde o começo. Inicialmente, descreveu um estado auto-erótico no qual a satisfação é obtida de forma parcial e desorganizada no próprio corpo. De acordo com a concepção do autor, este momento, anterior ao narcisismo, atesta que o eu ainda precisava ser desenvolvido. Para tal, Freud acrescentou que era necessária a ocorrência de uma "nova ação psíquica" (1914/2010, p. 19). Se recorrermos à concepção lacaniana do estádio do espelho, encontraremos subsídios para a compreensão da passagem do estado auto-erótico para o estado narcísico.

Sem fazer menção direta à formulação freudiana de 1914, concernente à nova ação psíquica, Lacan, em 1949, no artigo o estádio do espelho como formador da função do eu, recorre aos experimentos de Henry Wallon, realizados com crianças e animais frente ao espelho, com o intuito de ilustrar o nascimento do eu. O ponto de partida é que, diante do espelho, o bebê é captado pelo seu reflexo, reconhecendo-se na imagem percebida. De acordo com o raciocínio desenvolvido por Lacan, na operação especular assistimos ao nascimento do eu como constituição da imagem do corpo próprio; ao mesmo tempo em que o eu se constitui como unidade, a imagem especular é apreendida como objeto.

A experiência analisada por Lacan nos primeiros meses de vida do bebê humano, aproximadamente entre os seis e dezoito meses, sucede um período no qual o recém-nascido encontrava-se imerso num caos pulsional preexistente à constituição da imagem especular. Essa concepção demonstra que, através da imagem do corpo do outro vista em sua totalidade, o bebê obtém, por antecipação, a sensação de unificação corporal, passando do estado de auto-erotismo para o de narcisismo. Diante do espelho, a criança se depara com sua imagem tomada como objeto de investimento libidinal, e se identifica com esta. Tal imagem recebe um estatuto ideal, o que causa na criança uma atitude jubilatória, reflexo do momento em que se dá a captação ilusória especular.

O ideal encontrado na imagem nada mais é do que aquilo ilustrado por Freud, em Introdução ao narcisismo, como "Sua Majestade, o Bebê" (FREUD, 1914/2010, p. 37). Vale destacar que esta expressão exprime a ideia de que a criança "deve concretizar os sonhos não realizados de seus pais, tornar-se um grande homem ou herói no lugar de seu pai, desposar um príncipe como tardia compensação para a mãe" (idem). Seguindo esta linha de raciocínio, é possível entender que o eu ideal infantil pode ser tomado como equivalente ao ideal do eu paterno projetado sobre o bebê. Desta forma, diante do espelho, o eu ideal - objeto de afeição narcísica - só aparece refletido se for sustentado pelo ideal dos pais. Sendo assim, é somente um terceiro, geralmente a mãe, que sustenta a relação dual do eu com a sua imagem. Isto institui uma relação de dependência, já que a mãe é a responsável pela instauração deste processo.

De acordo com essa lógica, a concepção lacaniana do estádio do espelho pode ser entendida como uma identificação primordial, pois, quando a criança capta a imagem do outro unificada, ela antecipa o que desconhece de si, isto é, a gestalt de seu corpo. Nesse momento, o bebê experimenta um júbilo que, por sua vez, faz com que a imagem ganhe características de objeto: substancialidade, permanência e identidade. Deste modo, eu me torno imagem, havendo assim uma identificação narcísica onde o eu, ao identificar-se com a imagem refletida de si mesmo, torna-se objeto de valor cativante. 0 júbilo da criança pode ser entendido como revelador de um dinamismo libidinal que, ao mesmo tempo, atesta a emergência do eu e confere-lhe um destino alienado e preso a uma alteridade fornecedora da própria identidade. É nesse sentido que Lacan enfatiza o papel de Outro desempenhado pela mãe na dialética especular, já que esta funciona como um terceiro termo instaurador do desejo na relação imaginária. Em outras palavras, pode ser dito que, no processo de constituição da subjetividade, o desejo do Outro passa a ter prevalência sobre o sujeito.

Apesar de valorizar a dimensão alteritária como peça chave para a construção da subjetividade, Winnicott adotou uma perspectiva distinta para descrever a gênese do eu. Ao eleger como ponto de 
partida o conceito freudiano de narcisismo primário, Winnicott o concebeu como um estado em que o encontro com a dimensão alteritária e seus aspectos qualitativos desempenham papel fundamental. Com o intuito de esclarecer a importância do papel dessa dimensão na constituição do eu, Winnicott (1967/1975) busca subsídios em Lacan: “Sem dúvida, o artigo de Jacques Lacan, 'Le stade du miroir' (1949) me influenciou. Ele se refere ao uso do espelho no desenvolvimento do ego de cada indivíduo. Lacan, porém, não pensa no espelho em termos do rosto da mãe do modo como desejo fazer aqui" (WINNICOTT, 1967/1975, p. 153). A principal tese desenvolvida neste artigo é que, para ver o mundo, é necessário ter havido a experiência de ter sido objeto de investimento narcísico dos pais, ou, nos termos do autor, é necessário ter sido olhado.

O que vê o bebê quando olha para o rosto da mãe? Sugiro que, normalmente, o que o bebê vê é ele mesmo. Em outros termos, a mãe está olhando para o bebê e aquilo com o que ela se parece se acha relacionado como o que ela vê ali. (WINNICOTT, 1967/1975, p. 154).

Neste sentido, a mãe possui uma função especular, pois é com as respostas faciais presentes em seu rosto que o bebê se identifica e, gradualmente, vai constituindo um sentimento de eu. De acordo com Winnicott, no início da vida, a presença da alteridade não é percebida objetivamente, posto que ainda não há uma distinção eu/não-eu estabelecida. Isto implica que os objetos ainda não são percebidos como parte da realidade compartilhada nem como portadores de identidade e autonomia própria. Neste contexto, o relacionamento primário com a realidade acontece quando o bebê entra em contato com o objeto de forma subjetiva: "Do ponto de vista do bebê, nada existe além dele próprio, e, portanto, a mãe é inicialmente parte dele" (WINNICOTT, 1966/1996, p. 9). De acordo com a lógica estabelecida pelo autor, torna-se possível perceber que as qualidades da dimensão alteritária, presentes no rosto da mãe, são partes fundamentais e imprescindíveis do processo de construção dos contornos do eu e do sentimento de identidade.

Incluir na prática clínica a dimensão narcísica e, atrelado a esta, o tema dos primórdios da construção da subjetividade abriu um campo de pesquisa que possibilitou aos analistas pós-freudianos, das mais variadas orientações, inserir os sofrimentos narcísicos na cena psicanalítica. Tal inclusão implicou, entre outras coisas, trazer também para a prática clínica a dimensão não discursiva da experiência humana: as sensações, as inscrições corporais e relacionais que constituem o psiquismo antes da percepção de um eu auto-reflexivo e diferenciado de seu entorno. Algumas pesquisas (GALLESE, 2008; ROCHAT, 2004; STERN, 1992, 1997) mostram que o recém-nascido tece suas primeiras relações com o ambiente intermediado pelo ritmo, pelo toque, pelo cuidado e pela sintonia afetiva estabelecida pela mãe com suas necessidades corporais e afetivas. Isto quer dizer que, antes de representar e significar, o bebê se relaciona com seu entorno pelo contato instaurado por um tipo de comunicação baseada nas trocas sensíveis com o ambiente. Dentro desta perspectiva, é possível valorizar um plano no qual a inteligibilidade da experiência não se organiza pela mediação de uma reflexão sobre ela, mas, sim, pela percepção sensível dos modos pelos quais o mundo afeta a experiência do corpo e este afeta o mundo no qual ele age. Do ponto de vista ontológico, esta fase inaugura um campo fundamental da vida psíquica que perdurará ao longo da existência individual. $\mathrm{O}$ que acontece com a aquisição da linguagem é uma complexificação da experiência psíquica, que incorpora a este campo o universo infinito de significações. Sendo assim, o que vemos na vida de um sujeito é a existência concomitante e uma interação constante entre dois planos: o da experiência imediata, não discursiva, pré-reflexiva, não compartilhada; e o da experiência mediada pela significação, reflexiva e compartilhável.

Nos anos de 1972-73, em seu seminário Mais, ainda, Lacan consolidou um lugar para o corpo e para a dimensão não discursiva da experiência subjetiva. Para tal, adotou como ponto de partida a linguagem e a fala definidas como modalidades de gozo. Isto implicou que a linguagem passou a ser também teorizada como um conceito derivado em relação à lalangue - neologismo criado por Lacan que se tornou um dos operadores clínicos fundamentais deste seminário. O neologismo é construído a partir da junção do pronome francês la (em português, a) com a palavra francesa langue (em português, 
língua). Lalangue, traduzida para a versão dos seminários lacanianos em português por alíngua, contém em si a premissa de que é possível falar sem nada dizer, isto é, sem intenção significativa. No que se refere à articulação do neologismo em questão com a linguagem, Lacan esclarece: "Se eu disse que a linguagem é aquilo como o que o inconsciente é estruturado, é mesmo porque a linguagem, de começo, ela não existe. A linguagem é o que se tenta saber concernente à função de alíngua" (LACAN, 1972$3 / 1985$, p. 189). Nessa perspectiva, é possível conceber a linguagem como uma construção feita a partir de alíngua:

A linguagem, sem dúvida, é feita de alíngua. É uma elocubração de saber sobre alíngua. Mas o inconsciente é um saber, um saber-fazer com alíngua. E o que se sabe fazer com alíngua ultrapassa de muito o que podemos dar conta a título de linguagem. (LACAN, 1972-3/1985, p. 190).

Definida como fala ainda não inscrita no âmbito social da língua, alíngua concerne a manifestações da fala que não visam comunicação, nem reconhecimento e tampouco compreensão: “(...) é algo que resta indeciso entre o fonema, a palavra, a frase, mesmo todo pensamento" (LACAN, 1972-3/1985, p. 196). Alíngua consiste na primeira marca do ser falante; são os balbucios, as sílabas soltas que se repetem. Nesse sentido, alíngua pode ser entendida como um modo de satisfação que não depende da significação; em outros termos, como modalidade de gozo. A valorização dessa dimensão da experiência subjetiva possibilita uma ampliação do horizonte psicanalítico para além da representação e da estrutura do discurso como laço social, na medida em que torna possível incluir na clínica o campo não discursivo e, atrelado a ele, tudo o que escapa à teia das significações. Nessa direção, o inconsciente pode ser escrito a partir de um saber-fazer com alíngua.

Sendo assim, uma série de sensações, de inscrições corporais e relacionais que constituem o psiquismo antes da percepção de um eu auto-reflexivo pode servir como material para a clínica psicanalítica. Isto abriu um leque de possibilidades que vem incitando constantemente os psicanalistas a buscarem meios para construir modalidades de intervenção que contribuam para um alargamento do raio de ação da psicanálise.

\section{UM LUGAR PARA A DIMENSÃO NÃO-DISCURSIVA NO PROCESSO DE ASSOCIATIVIDADE}

Quando se trata de um tempo anterior ao estabelecimento da linguagem verbal, é preciso considerar uma época do desenvolvimento infantil que antecede o estabelecimento do status de unidade do eu. Nesse período, as experiências subjetivas são compostas por uma gama de estados provenientes de aspectos qualitativos suscitados pelas propriedades sensitivas que acompanham a percepção. Apesar de ainda não haver um nível de organização que permita integrar temporalmente as experiências e unificar as sensações corporais, já há a possibilidade de se ter a qualidade da experiência sentida como própria. Mesmo assim, ainda não há a possibilidade de compartilhar estas experiências a partir de uma narratividade construída em primeira pessoa nem por intermédio do relato verbal. $O$ processo de aquisição de sentido depende da integração de experiências que, embora não discursivamente organizadas, encontram-se articuladas, ordenadas e carregadas de sentido.

Em Sobre a concepção das afasias: um estudo crítico, Freud (1891/2013), apresentou a ideia de que a alteridade se constitui como peça fundamental para a construção das relações de sentido. Para dar corpo a essa concepção, foi elaborada, sem ser definida com precisão, a metáfora de um aparelho de linguagem. Neste texto, o aparelho de linguagem foi apresentado como um complexo associativo composto por representações construídas por meio de um conjunto de impressões cujo funcionamento se daria de forma semelhante a um aglomerado de dados adquiridos sensorialmente e organizados por cadeias associativas. De acordo com esta visada, a representação seria o resultado de um processo dinâmico, isto é, de sucessivos arranjos e rearranjos de informações sensoriais e não da reprodução psíquica das sensações e percepções apreendidas pelos órgãos sensoriais.

Sendo assim, na contramão das teorias elaboradas pela filosofia moderna que postulavam a atribuição de sentido como referencial, isto é, como algo dado pela realidade representada, Freud (1891/2013) concebeu a aquisição de sentido a partir de uma lógica associacionista, na qual o sentido não é dado, mas, sim, construído 
por dois tipos de representação: as representações-objeto e as representações-palavras ${ }^{2}$. Ao fazer referência ao primeiro tipo de representação, Freud muitas vezes utilizava, como sinônimo, o termo associação de objeto. Para entender a ideia principal contida na elaboração dessas noções, a palavra representação pode ser substituída por associação. Portanto, quando pensarmos em representação de objeto, podemos lançar mão da ideia de associações de objeto, posto que o que está em questão não designa o referente ou a coisa representada, mas, sim, o conjunto de imagens sensíveis que se agrupam para formar esta modalidade de representação. O fundamental desta noção reside no fato de que:

(...) a aparência de uma coisa, para cujas características concorrem aquelas impressões dos sentidos, somente se constitui na medida em que abarcamos, na soma das impressões dos sentidos que apreendemos de um objeto, a possibilidade de uma grande sequência de novas impressões na mesma cadeia (J. S. Mill). (FREUD, 1891/2013, p. 103).

A passagem transcrita deixa clara a influência do filósofo inglês no que diz respeito à concepção da metáfora do aparelho de linguagem. De acordo com Garcia-Roza (2014), é possível encontrar algumas ideias nos escritos de John Stuart Mill que influenciaram a concepção freudiana de que a representação-objeto contém apenas as qualidades despertadas pelo contato com a aparência dos objetos e que, sobretudo, esta não consiste na assunção de uma forma definitiva. Isto significa que, ao recebermos de uma coisa as impressões dos sentidos, a possibilidade de construção de uma sequência de novas impressões na cadeia associativa encontra-se aberta e pode ser refeita ininterruptamente. Tal fato nos permite entender que são as associações, ou as vias estabelecidas pelas associações, que vão constituir e ordenar o funcionamento do aparelho de linguagem. J. S. Mill estabelece a existência de alguns princípios que ordenam o funcionamento da cadeia associativa. São eles: semelhança, contiguidade, frequência e inseparabilidade. De forma breve, Garcia-Roza resumiu os dois primeiros princípios:

O princípio da semelhança afirma que as ideias semelhantes tendem a excitar-se mutuamente, formando um conjunto. O princípio da contiguidade afirma que, quando duas impressões foram frequentemente experimentadas ou pensadas simultaneamente ou em sucessão imediata, sempre que uma dessas impressões ou sua ideia se repetir, tenderá a excitar a ideia da outra. (GARCIA-ROZA, 2014, p. 156).

De acordo com esta lógica, é possível perceber que as representações-objeto geram transformações ininterruptas, permitindo, portanto, a existência, independente da realidade, de uma gama de representações que podem ser continuamente acessadas, ampliadas e associadas a outras representações. Sendo assim, não é o objeto em si que está sendo representado, mas, sim, as diferentes séries de associações que o compõe. É justamente neste sentido que Freud define este tipo de representação como um complexo aberto capaz de incluir as associações de imagens sensoriais. É aberto exatamente porque não fornece a identidade dos objetos. Esta só é fornecida a partir da ligação com a representação-palavra. De um outro ângulo, é possível observar que a representação-palavra só adquire significação a partir da ligação com a representação-objeto. A característica principal da representação-palavra consiste em ser concebida como um complexo representativo fechado, passível de ampliação, que reúne as associações de objeto, constituindo, assim, a identidade das coisas.

O que foi exposto acima revela um ponto crucial: a articulação dos dois tipos de representação tem um efeito de sentido. Isto significa que o significado é construído a partir da relação estabelecida entre representação-objeto e a representação-palavra, por intermédio da associação da imagem visual com a imagem acústica. Para esclarecer tal ideia, torna-se oportuno lançar mão do caso comentado por Freud, em 1895, no seu texto Projeto para uma psicologia científica. Com o intuito de explicar a compulsão fóbica de sua paciente, Freud (1895/1990) recorre a duas cenas: a primeira ocorreu na

2 Em 1915, a noção representação-objeto (FREUD, 1891/2013) passa a ser nomeada representação-coisa (FREUD, 1915/2010) e o termo representação-objeto fica reservado para demoninar o produto da associação estabelecida entre representação-coisa e representação-palavra. 
puberdade e a segunda, durante a infância. Na primeira cena, Emma entrou em uma loja e viu dois vendedores rindo juntos. Tomada por uma espécie de afeto de susto, saiu correndo da loja, pois julgou que os dois estavam rindo de suas roupas. A Freud, confessou que um deles a havia agradado sexualmente. A segunda cena recordada remontou à ocasião em que esteve desacompanhada em uma confeitaria e o proprietário agarrou-lhe as partes genitais por cima da roupa. Apesar disto, relatou que voltou na confeitaria mais uma vez. Entre as duas cenas, Emma estabeleceu um vínculo associativo: o riso.

(...) o riso dos vendedores a fez lembrar-se do sorriso com que o proprietário da confeitaria acompanhou sua investida. A marcha dos acontecimentos agora pode ser reconstituída. Na loja, os dois vendedores estavam rindo; esse riso evocou (inconscientemente) a lembrança do proprietário. De fato, a segunda situação tinha ainda outra semelhança [com a primeira]: ela mais uma vez estava sozinha em uma loja. Juntamente com o dono da confeitaria, lembrou-se de que ele a agarrara por cima da roupa; de que desde então ela alcançara a puberdade. A lembrança despertou o que ela certamente não era capaz na ocasião, uma liberação sexual, que se transformou em angústia. Devido a essa angústia, ela temeu que os vendedores da loja pudessem repetir o atentado e saiu correndo. (FREUD, 1950 [1895]/1990, p. 476).

A descrição acima deixa claro que o sentido de uma representação só é atribuído a partir da relação estabelecida com outras representações. Aqui é possível localizar a presença marcante da dimensão alteritária no processo de aquisição de sentido. Basta destacarmos o vínculo associativo estabelecido entre as duas cenas para notarmos que a do atentado sofrido na infância deixou impressas marcas que só puderam ser convertidas em representação-palavra a partir do momento em que um atentado sexual passou a ter sentido, isto é, no tempo da puberdade. Mais precisamente, quando o atentado passa a conter, em si, o significado sexual propriamente dito. É importante ressaltar que tal significado só adquiriu sentido para a paciente quando as inscrições do atentado sofrido na infância os vendedores, o riso e as roupas - foram acessadas pela memória e transcritas por intermédio da trilha associativa estabelecida a partir do assédio vivido na puberdade.

Cinco anos depois de ter concebido que o funcionamento do aparelho de linguagem é ordenado pelas vias associativas, Freud (1886-1899/1990), na carta 52, lança a hipótese de que os mecanismos psíquicos seguem uma lógica semelhante, posto que "o material presente em forma de traços de memória estaria sujeito, de tempos em tempos, a um rearranjo segundo novas circunstâncias - a uma retranscrição" (FREUD, 1886-1899/1990, p. 324). Para dar corpo a esta ideia, Freud concebeu que os mecanismos psíquicos se formam por um processo de estratificação que se desdobra em, pelo menos, três registros: o primeiro é constituído pelas impressões psíquicas decorrentes da percepção, associadas por simultaneidade e inacessíveis à consciência; a segunda inscrição, o registro da inconsciência, é composta por traços mnêmicos organizados, possivelmente, por causalidade; e o terceiro registro corresponde ao nosso eu reconhecido como tal, comportando, portanto, a préconsciência ligada à representação-palavra e, consequentemente, à linguagem verbal.

Diante das camadas apresentadas, é possível perceber que as duas primeiras dizem respeito ao que, no texto de 1891, foi definido como associações de objeto. Tal registro engloba as impressões que foram inscritas mas não transcritas, ou seja, que não foram representadas. Para se tornarem inteligíveis, adquirirem identidade e significação, é preciso que sejam ligadas às representações-palavra que, por sua vez, possuem a possibilidade de ser tornarem conscientes e integrarem-se ao eu. Freud (1886-1899/1990) concebe os três registros como três tipos de inscrição que, dinamicamente, vão se complexificando: dadas as circunstâncias, um rearranjo é efetuado e, consequentemente, uma retranscrição empreendida. É este movimento que ordena a integração do eu. Ao descrever este movimento, Freud (idem) deixa claro que, ao se passar de um registro a outro, a inscrição anterior não desaparece. Pelo contrário, Freud faz questão de enfatizar que "a memória não se faz presente de uma só vez, mas se desdobra em vários tempos; que ela é registrada em diferentes espécies de indicações" (ibidem, p. 324). 
O corolário disto é que nem tudo que pertence ao registro da inconsciência necessariamente tornar-se-á consciente. Portanto, nem tudo o que se encontra em um desses registros passará ao seguinte. Sendo assim, finalmente, chegamos ao ponto em que é possível afirmar que as experiências vividas antes do estabelecimento da representação-palavra ficam registradas sob a forma não-verbal e inscritas no psiquismo por meio da associação de imagens sensoriais.

\section{ESCUTANDO O NÃO-DITO: VARIAÇÕES DA TÉCNICA E DESDOBRAMENTOS CLÍNICOS}

Diante do que foi exposto, é possível supor que, baseado na lógica associacionista, Freud estabeleceu como regra fundamental para o funcionamento da associação livre a necessidade de o paciente transportar para o discurso verbal "tudo o que lhe vem à cabeça mesmo que seja desagradável dizê-lo, mesmo que lhe pareça sem importância ou realmente absurdo" (FREUD, 1940 [1938]/1990, p. 189). Deste modo, durante as sessões de análise, a regra fundamental obedece à lógica de funcionamento do aparelho de linguagem: (re)transcrições do material inconsciente são efetuadas a partir de sucessivos (re)arranjos associativos. O resultado do processo descrito acima pode ser a produção de sentido ou, também, a ampliação de significados existentes. Tais operações concederam à regra fundamental e, consequentemente, à expressão verbal do trabalho associativo, o estatuto de operador clínico.

Neste momento, cabe perguntar: como o analista pode ter acesso ao material registrado no psiquismo por meio de signos de percepção inscritos, mas ainda não organizados sob a forma de representação ${ }^{3}$ Tal questão que, a princípio, parece impor um limite, precisa ser transformada em possibilidade de trabalho. De acordo com a lógica estabelecida por Freud (1886-1899/1990), nem sempre o conjunto de imagens sensíveis agrupadas sob a forma de associações terá acesso à consciência. Isto significa que nem todo material ainda não representado e armazenado no inconsciente necessariamente será integrado ao eu e, consequentemente, transportado para o discurso verbal por intermédio da associação livre. Para obter acesso ao material não convertido em representação, torna-se necessário que o psicanalista amplie suas possibilidades de escuta, principalmente, no que diz respeito ao valor narrativo conferido ao material inconsciente inscrito sob a forma de imagens sensoriais.

Segundo Roussillon, um dos principais desafios para o alargamento do raio de ação da psicanálise contemporânea consiste em escutar, de forma polimorfa, a narratividade, constituída por uma mescla conteúdos verbais e não verbais, contida no processo de associatividade psíquica endereçado ao analista: "Se a regra da associação livre define a regra fundamental da psicanálise, o que a caracteriza mais fundamentalmente é o modo pelo qual ela é ouvida pelo analista" (ROUSSILLON, 2009, p. 144). Nesse sentido, as imagens acústicas, visuais, cenestésicas, gustativas e táteis, assim como os atos e manifestações corporais, devem ser entendidos como modos de narrações oriundos da dimensão subjetiva ainda não convertida em representação verbal. É justamente por conta disto que devem ser concebidos como formas potenciais de linguagem: "Potencial significa que elas só se tornarão formas plenas se forem entendidas e tratadas como tais" (ibidem, p. 145). A consequência disso é que o modo como a associatividade psíquica é escutada coloca em evidência o trabalho do analista, abrindo o caminho para a inserção da qualidade da presença deste no processo de associatividade.

\footnotetext{
${ }^{3}$ É necessário efetuar uma distinção entre os termos Vorstellung e Darstellung, ambos utilizados para fazer referência às diferentes acepções contidas na palavra representação. O vocábulo Darstellung foi traduzido como figura (no sentido de dar uma forma captável, figurar e/ou presentificar), devido ao fato de referir-se diretamente ao registro da apresentação como primeira forma de presença psíquica. Nesta acepção, o sentido de representação pode ser entendido como a constituição de uma forma apreensível, de uma forma capaz de presentificar (LEITE, 2001). Já Vorstellung, traduzida como representação, caracteriza uma reprodução, uma reevocação ou a colocação em cena de imagens já disponíveis e constituídas (idem). Esta acepção traz atrelada a si a possibilidade do uso de símbolos já que, com imagens constituídas, uma coisa pode ser colocada no lugar da outra.
} 
Como vimos, de acordo com a lógica estabelecida por Freud, para que um objeto possa ser representado, é necessário a presença de um outro aparelho de linguagem. É somente desta forma que a imagem visual do objeto pode ser associada à imagem acústica da palavra. Isto coloca em evidência a função da alteridade na significação dos conteúdos inconscientes ainda não representados sob a forma de palavra. Se transportarmos tal lógica para o trabalho de escuta de conteúdos não representados, é possível considerar a qualidade da presença do psicanalista como peça fundamental do processo de aquisição de sentido.

Para estabelecer conexões entre conteúdos não-representados, torna-se necessário que o analista participe, com sua presença sensível, do trabalho associativo. Isto inclui a totalidade de elementos que constituem o relacionamento analítico, dos quais a contratransferência e a neutralidade do analista merecem destaque. Numa visão ampliada, a contratransferência não se encontra limitada aos aspectos positivos e negativos produzidos pela transferência. Ela vai além e abrange todo o funcionamento psíquico do analista (HEIMANN, 1950). Desta forma, quando adicionada como um ingrediente à prática clínica, a presença do analista passa a incluir a qualidade de suas percepções, envolvendo, assim, mudanças de sensibilidade e de atenção. A partir desta lógica, ao participar da sessão com seus processos psíquicos, o analista utiliza o próprio funcionamento mental como ferramenta de trabalho.

De acordo com Paula Heimann (1950), na medida em que, durante a sessão, o inconsciente do analista engloba o do paciente, o psicanalista pode usar a contratransferência como um instrumento facilitador da compreensão do inconsciente do analisando. Usar a contratransferência como um instrumento facilitador da compreensão do inconsciente do analisando não significa admitir o abandono do conceito de neutralidade. Pelo contrário, se partirmos da diferença entre abstinência e neutralidade do analista (LOWENKRON, 1996), é possível conceber a presença do analista como uma forma de proximidade neutra. É importante lembrar que tal tipo de proximidade não diz respeito ao compartilhamento de experiências conscientes ligadas a valores estéticos ou juízos morais.

Seguindo essa lógica, a capacidade de identificação e de empatia ou, em outras palavras, a qualidade da presença do analista funciona como um ingrediente para garantir a extensão do método psicanalítico à escuta dos sofrimentos narcísicos. Sendo assim, para estes tipos de sofrimento, é preciso adaptar a técnica e, sobretudo, encarar o setting como parte integrante do analista, na medida em que este pode se constituir como peça fundamental para uma melhor compreensão de modos de subjetivação que encontram raízes nas experiências vividas nas fases mais precoces da constituição do psiquismo. Uma medida como esta permite alargar o horizonte de intervenções, incluindo possibilidades de ação que o uso do método psicanalítico clássico, que tem seu referencial teórico principal ancorado na interpretação das fantasias edípicas e de castração, não comporta.

Recebido em: 27 de maio de 2016. Aprovado em: 13 de agosto de 2017.

\section{REFERÊNCIAS}

BALINT, M. A falha básica: aspectos terapêuticos da regressão. Porto Alegre: Artes Médicas, 1967.

BION, W. R. A diferenciação entre a personalidade psicótica e a personalidade não-psicótica (1957). In: . Estudos psicanalíticos revisados. Rio de Janeiro: Imago, 1994.

FREUD, S. A repressão (1915). São Paulo: Companhia das letras, 2010 (Obras completas: Introdução ao narcisismo, ensaios de metapsicologia e outros textos, 12).

Conferência XXVII (1917[1916-17]). Rio de Janeiro: Imago, 1990. (Ed. standard brasileira das obras completas, 14). Conferência XXXIV (1933). Rio de Janeiro: Imago, 1990. (Ed. standard brasileira das obras completas, 22).

Esboço de Psicanálise (1940[1938]). Rio de Janeiro: Imago, 1990. (Ed. standard brasileira das obras completas, 23).

Projeto para uma psicologia científica (1895). Rio de Janeiro: Imago, 1990. (Ed. standard brasileira das obras completas, 1 ). 
. Publicações pré-psicanalíticas e esboços inéditos (1896). Rio de Janeiro: Imago, 1990. (Ed. standard brasileira das obras completas, 1).

Sobre a concepção das afasias: um estudo crítico (1891). Trad. Emiliano de Brito Rossi. Belo Horizonte: Autêntica, 2013. (Obras incompletas de Freud, 1).

GALLESE, V. Empathy, embodied simulation and the brain. Journal of the American Psychoanalytic Association, 56, 2008, 769-781.

GARCIA-ROZA, L. A. As afasias de 1891. In: Afasias: sobre a concepção das afasias. Freud, S. (1981). Rio de Janeiro: Zahar, 2014.

GREEN, A. Orientações para uma psicanálise contemporânea. Rio de Janeiro: Imago, 2008. HEIMANN, P. (1950). Counter-transference. British Journal of Medical Psychology , 33, 1950, p. 9-15.

HERZOG, R.; PACHECO-FERREIRA, F. De Édipo a Narciso: a técnica em questão. In: . De édipo a Narciso: a clínica e seus dispositivos. Rio de Janeiro: Cia. de Freud, 2014, p. $\overline{23-38}$

LACAN, J. Mais, ainda (1972-1973). In: . A ética da psicanálise. Rio de Janeiro: Jorge Zahar, 1985. (O seminário, 20).

O estádio do espelho como formador da função do eu (1949). In: Escritos. Rio de Janeiro: Jorge Zahar, 1998.

LEITE, E. P. B. A figura na clínica psicanalítica. São Paulo: Casa do Psicólogo, 2001.

LOWENKRON, A. M. Sobre o início da análise de crianças: algumas particularidades. Revista Brasileira de Psicanálise, 30 (1), 1996, p. 27-34.

ROCHAT, P. The infant's worlds. Cambridge: Havard University Press, 2004.

ROUSSILLON, R. Associatividade e as linguagens não-verbais. 2009. Disponível em: <https://reneroussillon.files.wordpress.com/2014/08/rr_assoclinguagens_nao_verbais_revis ta-sppa-v16-n1-2009.pdf>. Acesso em: 15 maio 2016. $\overline{100-120 .}$

Situations et configurations transferrentielles limites. Fliligrane, v. 8, n. 2, 1999, p.

STERN, D. A constelação da maternidade. Porto Alegre: Artes Médicas, 1997.

O mundo interpessoal do bebê. Porto Alegre: Artes Médicas, 1992.

VERTZMAN, J. et al (orgs). Sofrimentos narcísicos. Rio de Janeiro: Companhia de Freud, 2012, p. 9-312.

WINNICOTT, D. W. A mãe dedicada comum. In: . Os bebês e suas mães. São Paulo: Martins Fontes, 1996.

O papel de espelho da mãe no desenvolvimento da criança e da família (1967). In: O brincar e a realidade. Rio de Janeiro: Imago, 1975.

Psicose e cuidados maternos (1952). In: . Da pediatria à psicanálise. Rio de Janeiro: Imago, 2000.

\section{Perla Klautau}

pklautau@uol.com.br 